\title{
Direito e SaÚde: A disCRICIONARIEDADE NAS AÇões FiSCAIS DA VIGILÂNCIA SANITÁRIA DE ALIMENTOS
}

\author{
RIGHT AND HEALTH: THE DISCRETIONARY ACTS IN FOOD \\ INSPECTION BYTHE SANITARY VIGILANCE
}

\author{
Rinaldini C. Philippo Tancredi $\left.{ }^{*}\right)$ \\ Andrea Fonseca Barreto ${ }^{(* *)}$ \\ José Geraldo Rangel Tancredi ${ }^{(* * *)}$
}

\section{RESUMO}

A Ciência do Direito orienta-se por princípios os quais constituem a base que rege todas as relações jurídicas existentes. À Vigilância Sanitária e ao Sistema Único de Saúde cabem a responsabilidade pelas ações de fiscalização e inspeção de alimentos, bebidas, águas de consumo, embalagens e matérias-primas alimentares, além dos estabelecimentos industriais e comerciais de alimentos, com o propósito de prevenir riscos à saúde do consumidor. As normas jurídicas sobre alimentos são complexas e abrangentes e, em várias situações, não muito claras, delegando ao agente responsável pela ação fiscal a interpretação do texto legislativo e a aplicabilidade da sanção ou penalidade que melhor couber ao caso. Busca-se neste trabalho, identificar e compreender a utilização dos atos administrativos enquanto normas aplicadas à Vigilância Sanitária, no Sistema Federativo Brasileiro, no desenvolvimento das atividades rotineiras. Conclui-se que a discricionariedade administrativa, permitida nas ações fiscais da Vigilância Sanitária, justifica-se pela ampla variedade e quantidade de problemas a serem equacionados pelos agentes na sua jornada de trabalho, para os

(*) Médica Veterinária da Superintendência de Controle de Zoonoses, Vigilância e Fiscalização Sanitária da Secretaria Municipal de Saúde da Prefeitura da Cidade do Rio de Janeiro - SMS/RJ; professora adjunta do Departamento de Tecnologia de Alimentos da UNIRIO, doutora em Vigilância Sanitária pelo INCQS/FIOCRUZ/MS. E-mail: <rtancredi@globo.com>.

$\left({ }^{\star \star}\right)$ Advogada formada pela Universidade Cândido Mendes - UCM/RJ, Especialista em Direito do Consumidor pela PUC/Rio.

$\left(^{\star \star *}\right)$ Médico Veterinário da Superintendência de Controle de Zoonoses, Vigilância e Fiscalização Sanitária da Secretaria Municipal de Saúde da Prefeitura da Cidade do Rio de Janeiro - SMS/RJ.1; bacharel em Direito pela Sociedade Universitária Augusto Motta - SUAM/RJ. 
quais a lei, por mais abrangente e completa, nem sempre tem respostas, cabendo aos agentes tomar as medidas mais adequadas a cada caso, de acordo com o seu conhecimento técnico-científico e senso comum.

\section{Palavras-chave}

Inspeção de Alimentos; Normas Jurídicas; Vigilância Sanitária.

\section{ABSTRACT}

The Science of the Right is oriented for principles which constitute the base that conducts all the existing legal relationships. The sanitary vigilance and the National Health System are in charge of the actions of fiscalization and food inspection, alimentary drinks, water for human consumer, packings and raw materials, beyond the industrial and commercial establishments of foods, with the intention to prevent risks to the health of the consumer. The rules regarding food are complex and enclosed however, in some situations, they are not very clear, which delegates the responsibility for the agents of interpretating the legislative text and of taking the necessary actions, such as sanctions, that better fit to the case. This works searches to to identify and to understand the use of the administrative acts while they are rules applied to the sanitary vigilance, inside the Brazilian Federative System, during the routine activities. It is concluded that the administrative arbitrarierity allowed in actions of fiscalization of the sanitary vigilance justifies due to the variety and amount of problems to be equalized for the agents in their job. Even the most complete law has not all the answers for these questions and it is a responsibility of the agents to take the measures that better adjust to each case, in accordance with their technician-scientific knowledge and common sense.

\section{Key words}

Food Inspection; Health Surveillance; Law Rules.

\section{INTRODUÇÃO}

O Direito, dentre outras definições, pode ser entendido como o conjunto de regras adotado por um determinado grupo social, num determinado período histórico, espacial e socioeconômico, concernentes a regular e viabilizar a própria existência da sociedade e com o objetivo de "minimizar ao máximo" a colisão entre os interesses individuais e coletivos, o que levaria 
ao caos social e, conseqüentemente, ao próprio perecimento da sociedade.Toda ciência do Direito orienta-se sustentada por princípios em sua estrutura fundamental, constituindo a base que deve reger todas as relações jurídicas existentes. No campo da administração pública não pode ser diferente, uma vez que esta só existe a partir do momento em que se apresenta legalmente regulada.

A ação de fiscalizar ou inspecionar alimentos, bebidas, águas de consumo, embalagens e matérias-primas alimentares, além dos estabelecimentos industriais e comerciais de alimentos, com o propósito de prevenir riscos à saúde do consumidor, é competência da Vigilância Sanitária e do Sistema Único de Saúde. Assim, o ato de inspecionar, ou fiscalizar, é compreendido como a ação verificadora do cumprimento da legislação sanitária frente às atividades da cadeia de produção, distribuição e comercialização de forma a assegurar o direito do consumidor na prevenção de riscos oriundos do consumo de alimentos, bebidas e águas. Este direito vem claramente explicitado na Lei n. 9.782 de 1999, do Ministério da Saúde, ao definir o Sistema Nacional de Vigilância Sanitária(1).

As normas jurídicas sobre alimentos são complexas e abrangentes e, em várias situações, não muito claras, delegando ao agente responsável pela ação fiscal a interpretação do texto legislativo e a aplicabilidade da sanção ou penalidade que melhor couber ao caso. Ou seja, ao contrário do ato vinculado que obedece inteiramente aos ditames da lei, o ato discricionário não é totalmente determinado pela norma legal, implicando (faixa de autonomia) a verificação de conveniência e oportunidade (concedida ao) pelo agente fiscal público. A rigor, a discricionariedade não se manifesta no ato em si, mas sim no poder da administração em praticá-lo pela maneira e nas condições que repute mais convenientes ao interesse público, conforme ressalta Meirelles (1993) ${ }^{(2)}$.

A origem dos autos de infração sanitária, extraídos na rotina das ações fiscais, na área de controle de alimentos, pela Vigilância Sanitária, dá-se pela aplicação aos artigos infringidos do Decreto-Lei n. 986/69 do Ministério da Saúde e também através de decretos específicos aprovados pelos Municípios e utilizados no âmbito de sua jurisdição. Para Elias $(2004)^{(3)}$, o Direito Tributário Sanitário compõe-se de regras jurídicas de natureza tributária criadas especificamente com a finalidade de fomento ao sistema de fiscalização sanitário federal, ocorrendo o mesmo nos municípios brasileiros.

(1) BRASIL. Ministério da Saúde. Lei n. 9.872, de 26 de janeiro de 1999, define o Sistema Nacional de Vigilância Sanitária e cria a Agência Nacional de Vigilância Sanitária (ANVISA), substituindo a Medida Provisória n. 1.791 de 1998, aprovada pelo Congresso Nacional.

(2) MEIRELLES, Hely Lopes. Direito administrativo. 8. ed. atual. por Eurico de Andrade Azevedo, Délcio Balestero Aleixo e José Emmanuel Burle Filho. São Paulo: Malheiros Ed., 1993. p. 102-104. (3) ELIAS, Alexandre Nemer. Direito tributário sanitário: das taxas de fiscalização sanitária e seus problemas atuais - uma forma de identificação dos erros na busca de soluções. Revista de Direito Sanitário, São Paulo, v. 5, n. 3, p. 99-113, nov. 2004. 
Busca-se neste trabalho facilitar a compreensão e, consequentemente, a utilização dos atos administrativos, enquanto normas aplicadas à vigilância sanitária, no Sistema Federativo, e no desenvolvimento de suas atividades rotineiras, em especial na área de alimentos. Objetiva-se neste estudo na tentativa de esclarecer, de forma sucinta, que o atributo da discricionariedade está longe de ser simplesmente um "poder", mas sim um "dever", no sentido de olhar de forma diferenciada as várias formas de agir, penalizar e corrigir do agente fiscal da Vigilância Sanitária, uma vez que a essência da discricionariedade permite maior contribuição e desenvolvimento de ações preventivas em detrimento daquelas de caráter essencialmente punitivas.

\section{O DIREITO À SAÚdE INDIVIDUAL E COLETIVA}

Dentre as regras adotadas pela sociedade como justas e legítimas (legitimidade no sentido apresentado por Diogo de Figueiredo Moreira Neto ${ }^{(4)}$, como estabilização do poder em torno de valores consensualmente aceitos), existe a regra maior que se apresenta através da Constituição da República Federativa do Brasil (CRFB/88) ${ }^{(5)}$, pela qual se estabelece a saúde como um direito de todos (social) e dever do Estado. A partir dessa afirmação feita pelo Poder Constituinte originário do atual Estado Democrático de Direito Brasileiro, depreende-se a transformação de uma ordem ético-política (legitimidade) em uma ordem ético-jurídica (legalidade), com normas coativamente impostas, não só à sociedade, como também e, principalmente, ao Estado, no tocante à saúde pública e individual.

Assim, com a transformação de legitimidade para legalidade no preceito saúde pública e individual, esta passa a comportar o status de bem jurídico legalmente tutelado, fazendo com que o direito à saúde se torne algo exigível da sociedade perante o Estado, bem como do Estado perante a sociedade, onde ambos os entes possuem o poder/dever de exigirem, mutuamente, que a saúde de todos seja integralmente preservada e garantida, não só na esfera administrativa, mas também, subsidiariamente, na esfera judicial, quando esgotados todos os recursos administrativos.

\section{DOS PRINCÍPIOS ADMINISTRATIVOS E JURÍDICOS NAS AÇÕES DA VIGILÂNCIA SANITÁRIA}

A escolha pela regência de princípios, em uma ciência tão dinâmica e dialética como o Direito, mostra-se fundamental, porque, através dos princí-

(4) MOREIRA NETO, Diogo Figueiredo. Legitimidade e discricionariedade: novas reflexões sobre os limites e controle da discricionariedade. 4. ed. Rio de Janeiro: Forense, 2002. p. 103.

(5) BRASIL. Constituição da República Federativa do Brasil, promulgada em 1988. 
pios jurídicos adotados pela sociedade, todo o sistema legal deverá estabelecer-se, sob pena de inconstitucionalidade normativa; bem como a adoção de princípios evita (ou pelo menos minimiza) o abuso do poder legisferante em editar normas que atentem contra a legitimidade já estabelecida. A administração pública e seus princípios básicos encontram-se elencados no art. 37, caput da CRFB/88; princípios estes sobre os quais faremos algumas breves colocações:

Princípio da Legalidade - Base da administração pública, este principio, antes de estar previsto no art. 37, caput CRFB/88, concernente à administração pública, foi estabelecido pelo Poder Constituinte Originário no art. 5, II da CRFB/88, como sendo regra que faz parte dos direitos e garantias fundamentais e estabelece que ninguém é obrigado a fazer ou deixar de fazer alguma coisa senão em virtude de lei. A partir desta colocação, torna-se claro que a administração pública só pode atuar autorizada por lei; sua vontade deve ser a vontade decorrente da lei. Ao contrário do administrado que pode agir sob o fundamento de que determinado ato não seja proibido por lei - já que no campo do Direito Privado o que prevalece é a autonomia da vontade e não o interesse público - a administração pública deve sempre agir com a finalidade de alcançar o interesse público e só pode operar respaldada em lei vigente.

Princípio da Impessoalidade - Este denota que a atuação da administração pública não pode visar à satisfação de interesses pessoais do administrador (agente público), nem do administrado. O que se deve ter sempre em mente é a satisfação do interesse público de forma ótima; motivo, afinal, da existência da máquina do Estado.

Princípio da Moralidade - Chegamos ao conceito de moralidade administrativa, dentre outras maneiras, a partir do seu oposto, ou seja, a imoralidade administrativa, que está vinculada à idéia de desvio de poder, onde a Administração utiliza-se de meios superficialmente lícitos para atingir finalidades jurídicas e morais irregulares. A título de exemplo, podemos citar o caso de um determinado político promover a edição de lei exigindo que certo produto, utilizado em bares e restaurantes, apresente-se em embalagem específica, que, por acaso, só é fornecida por fábrica de propriedade deste político ou de sua família. Apesar da exigência estar embasada em lei, por causa das circunstâncias que a norteiam, esta não se mostra legítima, e, portanto, contraria o princípio da moralidade administrativa.

Princípio da Publicidade - Este exige a ampla divulgação de todos os atos praticados pela administração pública, exceto, como previsto no inciso $L X$, do art. $5^{\circ}$ da CRFB/88, quando a defesa da intimidade ou o interesse social exigirem o sigilo. A publicidade dos atos administrativos está relacionada, inclusive, com a publicidade meramente interna dos órgãos da administração. Sendo assim, para que um ato administrativo possa ser considerado válido e eficaz, imprescindível é que se torne público (com exceção 
das hipóteses de sigilo constitucionalmente admitidas), a fim de que possa haver um controle não só sobre a administração, como também da administração, uma vez que os atos, negócios, convênios e outros celebrados por ela, e tornados públicos, possibilitam um controle pelo particular, que poderá impugná-los administrativa e até judicialmente.

Princípio da Eficiência - O princípio da eficiência tem que ser observado sob duas óticas: eficiência no sentido de que o agente público deve atuar de forma a sempre visar ao ótimo para o interesse público: não basta que seja boa, sua atuação deve ser ótima, ou seja, deve-se fazer uso dos meios e das formas mais adequadas para o alcance da finalidade pública, evitando ao máximo protelar o exercício de seu dever com burocracias excessivas e desnecessárias; e há também a eficiência no sentido de que a máquina administrativa deve apresentar-se na sua melhor organização, estrutura e gestão, atualizando-se e modernizando-se, sempre com o intuito de ultrapassar o peso burocrático que, na maioria das vezes, impede que o interesse público seja alcançado a tempo de efetivamente fazer cumprir seu papel na sociedade.

Além dos princípios básicos da administração pública, definidos no art. 37 caput da CRFB/88, o agente fiscal da Vigilância Sanitária deve ter sempre em mente que ainda somam-se outros princípios expressos ou implícitos na CRFB/88, como a Presunção de Legitimidade ou Veracidade, Especialidade, Controle ou Tutela, Autotutela, Hierarquia, Continuidade do Serviço Público, Razoabilidade e Proporcionalidade, Motivação, Segurança Jurídica, entre outros, os quais devem ser profundamente conhecidos pelo agente público (fiscal), a fim de se evitar que seus atos executórios comprometam um ou alguns desses princípios já mencionados e padeçam de vícios, tornando-os nulos ou anuláveis (dependendo do caso concreto), infringindo o princípio da eficiência e podendo trazer conseqüências, não só administrativas, como também cíveis e criminais as quais incluem desde o descrédito da administração pública e de seus agentes públicos, até o ressarcimento do prejuízo causado ao particular, prejuízo este que, conforme estabelece $\circ$ art. $36, \S 6^{\circ}, \mathrm{CRFB} / 88$, está assegurado à administração o direito de regresso contra o(s) responsável(eis) nos casos de dolo e culpa.

\section{AS REGULAMENTAÇÕES SANITÁRIAS NA VIGILÂNCIA SANITÁRIA DE ALIMENTOS}

Os Estados e Municípios são competentes para suplementar a legislação sanitária aprovada pela União, cabendo aos Municipios aprovar e aplicar regulamentações sobre assuntos de interesse local, no sentido de preservar a saúde de seus munícipes. A legislação sanitária vigente serve de parâmetro para traçar limites de controles. As regulamentações sanitárias, também denominadas leis no aspecto genérico, podem se apresentar 
sob diferentes formas quanto à origem, conteúdo e hierarquia, diferenciandose assim também suas aplicabilidades.

A validade ou competência do ato administrativo emana do poder atribuído ao agente administrativo para o desempenho de suas funções no interesse público. Para cada ato administrativo existe uma forma própria no que diz respeito à hierarquia, origem, extensão territorial e conteúdo. As leis podem ser, de forma geral, complementares e ordinárias e os decretos são atos administrativos que facilitam a sua aplicação.

A organização constitucional do Sistema Nacional de Saúde prevê que "as ações e serviços de saúde" integram uma rede regionalizada e hierarquizada num Sistema Único de Saúde, conforme art. 198 da Constituição Federal vigente, deixando claro a competência das três esferas de poder público da federação: União, Estados e Municípios. Também prevê que a obrigação de editar normas de "proteção e defesa da saúde" é competência concorrente dessas mesmas esferas. Isto significa, de acordo com Dallari $(2000)^{(6)}$, que "cuidar da saúde" é tarefa de todos. Assim sendo, cabe à União produzir e aprovar normas gerais, que devem ser suplementadas pelos Estados, as quais, por sua vez, serão complementadas por normas elaboradas e aprovadas pelos Municípios.

$\mathrm{Na}$ área da Vigilância Sanitária de alimentos, temos como referência o Codex Alimentarius Commission, no âmbito da competência da Organização das Nações Unidas para a Agricultura e Alimentação (FAO) e da Organização Mundial de Saúde, que considera os múltiplos aspectos da produção alimentar, como as garantias sanitárias aos protocolos científicos e comercias, e tem como objetivo fixar parâmetros ou padrões precisos relacionados com a presença de microrganismos ou com resíduos de agrotóxicos, além das medidas preventivas referentes à avaliação de risco, visando à segurança alimentar, conforme destaca Custódio $^{(7)}$, em 2003. A mesma autora afirma, aindam que para salvaguardar os consumidores, o citado código seleciona e fixa as regras gerais para a etiquetagem ou rotulagem e a confecção dos produtos de forma compatível com as normas internacionais de higiene alimentar, no sentido de garantir a qualidade do alimento do ponto de vista sanitário.

As formas de apresentação das disposições normativas, com objetivo de "fixar as regras", quanto a sua origem, conteúdo e aplicabilidade, de ordem geral, nas ações de Vigilância Sanitária, podem variar entre: leis, decretos, resoluções e portarias, com origens emanadas pelo Poder Legis-

(6) DALLARI, Sueli Gandolfi. Organização jurídica da administração pública em saúde. In: ROZENFELD, S. (Org.) Fundamentos da vigilância sanitária. Rio de Janeiro. Ed. FIOCRUZ, 2000. p. 113-133.

(7) CUSTÓDIO, Helita Barreira. Direito do consumidor e os organismos geneticamente modificados. Revista de Direito Sanitário, São Paulo, v. 4, n. 3, p. 62-94, nov. 2003. 
lativo, chefes do executivo, Poder Executivo e autoridades outras que não o chefe do executivo, como, por exemplo: ministros, secretários e ainda colegiados. No sentido ainda de fornecer comunicações de teor uniforme encaminhadas ao conjunto de pessoas ou no caso agentes públicos da Vigilância Sanitária, com o objetivo de cumprir de forma adequada e uniforme as normas técnicas e sanitárias são utilizadas circulares e ordens de serviço, com competência das chefias de órgãos, repartições ou serviços (Meirelles, 1993).

Os documentos passíveis de serem extraídos nas ações de controle ou fiscais em Vigilância Sanitária na área de alimentos são: Termo de Visita Sanitária, que visa identificar e descrever o estabelecimento inspecionado, identificar o órgão fiscalizador e os agentes e especificar o motivo da ação fiscal e as medidas adotadas; Termo de Intimação, descreve as exigências estruturais e emergenciais do estabelecimento e fixa prazos para cumprimento; Termo de Apreensão de Inutilização ou Depósito, identifica os produtos apreendidos ou inutilizados e, geralmente, está vinculado ao Auto de Infração; Auto de Infração, cita o artigo infringido e descreve a infração cometida e o valor de multa da penalidade; Edital de Interdição, identifica o estabelecimento e o local, total ou parcialmente interditado, além do prazo da interdição; Termo de Apreensão de Amostra para Análise, identifica o produto a ser colhido para análise laboratorial, o motivo da coleta, as condições do produto e o tipo de análise bem como o laboratório oficial que realizará a análise (RIO DE JANEIRO, 1986 e 1994)(8).

$\mathrm{Na}$ área de alimentos os regulamentos são inúmeros, alguns de caráter amplo e outros específicos por assuntos de instâncias federais, estaduais e municipais. Alguns regulamentos apresentam conteúdos semelhantes, com vários artigos citando o mesmo teor no tocante ao fato descrito, permitindo assim interpretações diferentes na aplicação das penalidades e na citação dos artigos, como, por exemplo, o número de vezes que uma infração deve ser declarada ao se aplicar o mesmo fato para produtos, ambientes ou situações diferentes, em relação ao descumprimento das normas sanitárias. E, por vezes, a mesma situação pode ser interpretada de forma diferente pelos agentes pertencentes ao mesmo Serviço de Vigilância Sanitária, uma vez que embutem critérios subjetivos e niveis diferenciados de conhecimentos, na avaliação das condições higiênico-sanitárias.

\section{A DISCRICIONARIEDADE ADMINISTRATIVA COMO PODER/DEVER}

Para o desempenho de suas funções no organismo estatal, a administração pública dispõe de poderes que lhe asseguram posição de supre-

(8) RIO DE JANEIRO, 1986 (Município) Secretaria Municipal de Saúde, Decreto n. 6.235, de 30 de outubro de 1986. Aprova o Regulamento da Defesa e Proteção da Saúde no Tocante a Alimentos e à Higiene Habitacional e Ambiental. RIO DE JANEIRO, (Município) Secretaria Municipal de Saúde, Resolução n. 492, de 19 de outubro de 1994. Aprova e adota o Termo de Visita Sanitária. Diário Oficial do Municipio do Rio de Janeiro, 21 de outubro de 1994. 
macia sobre o particular; no entanto, os poderes que exerce o administrador público são regrados pelo sistema jurídico vigente, não podendo a autoridade ultrapassar os limites que a lei traça a sua atividade, sob pena de ilegalidade. Porém, o regramento não atinge todos os aspectos da atuação administrativa e a lei deixa certa margem de liberdade de decisão diante do caso concreto, de tal modo que a autoridade poderá optar por uma dentre várias soluções possiveis, todas válidas perante o Direito.

Poder discricionário é o que o Direito concede à administração, de modo explícito ou implícito, para a prática de atos administrativos com liberdade na escolha de sua conveniência, oportunidade e conteúdo (Meirelles, 1993). Nesses casos o poder de administração é discricionário, porque a adoção de uma ou outra solução é feita segundo critérios de oportunidade, conveniência, justiça e eqüidade próprios da autoridade, porque não definidos pelo legislador. Entretanto, o poder de ação administrativa, embora discricionário, não é totalmente livre, pois, sob alguns aspectos, em especial a competência, a forma e a finalidade, a lei impõe limitações. Daí, na interpretação de Di Pietro (2002) ${ }^{(9)}$, a discricionariedade implica liberdade de atuação nos limites traçados pela lei; entretanto, se a administração ultrapassa esses limites, a sua decisão passa a ser arbitrária, ou seja, contrária à própria lei.

A própria norma jurídica contém, em muitos casos, conceitos expressos por termos ambíguos ou imprecisos. Em particular quanto à atividade administrativa de implementação de políticas públicas. Dada a variabilidade, no tempo e no espaço, das necessidades coletivas, os conceitos abertos seduzem o legislador, uma vez que estes conceitos se amoldam à exigência de reação administrativa conveniente e oportuna àquelas necessidades. Torna-se, portanto, imprescindivel reconhecer a necessidade da discricionariedade na função administrativa, para poder julgar a legalidade dos atos decorrentes da aplicação de conceitos vagos (Dallari, 2000). Didaticamente, a matéria relativa à discricionariedade administrativa vem inserida nos capítulos dos "Poderes da Administração", levando o observador a ter a falsa impressão de que se trata de um poder conferido ao administrador para ser usado sobre o administrado, não restando a esse último, outra alternativa, a não ser acatar e obedecer ao que foi decidido de forma discricionária pelo primeiro. No entanto, dificilmente encontramos um ato administrativo inteiramente vinculado, porque haverá sempre aspectos sobre os quais a administração terá opções na sua realização. Mas o que caracteriza o ato vinculado é a dominância de especificações da lei sobre os elementos deixados livres para a administração (Meirelles, 1993).

$O$ poder conferido à discricionariedade sugere o entendimento de faculdade, no sentido de que o detentor do poder (fiscal da Vigilância Sani-

(9) DI PIETRO, Maria Sylvia Zanella. Direito administrativo. 14. ed. São Paulo: Ed. Atlas, 2001. p. 204-208. 
tária) poderia livremente escolher ao seu juízo de conveniência. Porém, o poder conferido ao agente público no exercício da discricionariedade não se encerra em mera faculdade e juizo de conveniência particulares do agente público. O que o fiscal deve sempre atentar é que o poder por ele exercido possui limites e subordinações à lei e aos seus princípios correlatos, bem como a uma finalidade específica, qual seja, o interesse público.

Não existe discricionariedade absoluta, ela sempre deverá estar vinculada ao fim a que se destina e à eleição da melhor solução dentre as apresentadas pela norma, no caso concreto, respaldado não só na legalidade, como também na legitimidade.

Com relação ao dever atribuído ao ato discricionário, este se revela como a obrigação assumida pelo agente público ou fiscal da Vigilância Sanitária de velar sempre pelo interesse público, atuando de forma eficiente, já que um dos fundamentos da discricionariedade reside no fato de estar o agente público mais capacitado a escolher a alternativa que melhor atinja a finalidade pública, por ser impossivel ao legislador prever todos os desdobramentos fáticos que as relações humanas podem comportar. Sendo assim, podemos nos arriscar a dizer, como ensina Celso Antônio Bandeira de $M e l l{ }^{(10)}$, que o "poder" conferido aos atos discricionários se baseia no "dever" que tem o agente público de alcançar a finalidade legal e o bem comum.

O agente fiscal da Vigilância Sanitária deve ter sempre em mente que o uso de forma ilícita do poder/dever conferido à discricionariedade traz, como conseqüência, o abuso de poder e a ilegalidade do ato praticado, podendo este abuso advir da incompetência (lato sensu) do agente, finalidade do ato distinta da que realmente deveria ser perseguida, ou da execução do ato de forma equivocada. Assim, reforça Carvalho et al..(11): "Se é verdade que à Administração é confiado o poder de polícia, também é verdade que este tem limites, e deve ser exercido de forma ética e legal, sem qualquer tipo de abuso, ainda mais que a própria lei, como já visto, prevê os procedimentos a serem tomados nos casos de inviabilidade da notificação pessoa". Destaca, ainda, Meirelles (1993) que a discricionariedade administrativa encontra fundamento e justificativa na complexidade e variedade dos problemas que o poder público tem para solucionar a cada passo e para os quais a lei, por mais casuística que fosse, não poderia prever todas as soluções, ou pelo menos a mais vantajosa para cada caso ocorrente.

Mediante o exposto e o imenso arcabouço e caminhos a serem tomados no bojo dos atos discricionários, fica clara a necessidade do indispensável conhecimento da Teoria Geral do Direito e seus princípios correlatos

(10) MELLO, Celso Antonio Bandeira de. Discricionariedade administrativa e controle judicial. Revista de Direito Público, São Paulo n.33, p. 85-98, jan./mar. 1975.

(11) CARVALHO, Cristiano; MACHADO, Rafael Bicca; TIMM, Luciano Benetti. Direito sanitário brasileiro. São Paulo: Ed.Quartier Latin, 2004. p. 12-13. 
(principalmente os administrativos) pelo agente fiscalizador da Vigilância Sanitária, no exercício das suas atividades e da discricionariedade que the é atribuída pela lei na área da vigilância e, conseqüentemente, nas atividades relacionadas ao controle de alimentos.

Torna-se mais dedutivel a interpretação sobre a inviabilidade das leis vigentes, e as que porventura venham a ser editadas, trazerem em seu conteúdo previsão de situações fechadas e encerradas em si mesmas, levando-se em conta as constantes evoluções tecnológicas e sociais, raízes de uma sociedade amplamente dinâmica e dialética.

\section{CONCLUSÃO}

O atributo da discricionariedade está longe de ser simplesmente um "poder"; mas sim é um "dever" que precisa ser encarado pelo agente fiscal da Vigilância Sanitária sob estas duas vertentes, chegando-se assim à essência do atributo da discricionariedade, o qual revela-se como verdadeiro "poder/dever" da administração pública. A discricionariedade ou os atos discricionários administrativos, permitidos nas ações fiscais da Vigilância Sanitária, justificam-se pela ampla variedade e quantidade dos problemas a serem equacionados pelos agentes, durante sua jornada de trabalho, sempre com o principal objetivo de prevenir riscos à saúde da coletividade. Importante destacar que, a lei, por mais abrangente e completa, não tem respostas a todas as questões, cabendo aos agentes a tomada de medidas mais adequadas, para a solução e controle de cada caso, de acordo com o seu conhecimento técnico-científico e senso comum no seu território de atuação. Portanto, a discricionariedade não pode servir de desculpa ou pretexto para decisões arbitrárias e ineficientes, que não atendam à demanda do interesse público ou aos objetivos contidos nos regulamentos sanitários, de forma eficiente e satisfatória.

\section{REFERÊNCIAS}

MELLO, Celso Antonio Bandeira de. Discricionariedade administrativa e controle judicial. Revista de Direito Público, São Paulo, n. 33, p. 85-98, jan./ mar. 1975.

CARTANA, A. P. Processo administrativo sanitário: teoria e prática. Porto Alegre: Ed. Alcance, 2000.

CARVALHO, Cristiano; MACHADO, Rafael Bicca; TIMM, Luciano Benetti. Direito sanitário brasileiro. São Paulo: Ed.Quartier Latin, 2004.

CUSTÓDIO, Helita Barreira. Direito do consumidor e os organismos geneticamente modificados. Revista de Direito Sanitário, São Paulo, v. 4, n. 3, nov. p. 62-94, 2003. 
DALLARI, Sueli Gandolfi. Organização jurídica da administração pública em saúde. In: ROZENFELD, S. (Org.) Fundamentos da vigilância sanitária. Rio de Janeiro: Ed. FIOCRUZ, 2000. p. 113-133.

DI PIETRO, Maria Sylvia Zanella. Direito administrativo. 14. ed. São Paulo: Atlas, 2001.

ELIAS, Alexandre Nemer. Direito tributário sanitário - das taxas de fiscalização sanitária e seus problemas atuais - uma forma de identificação dos erros na busca de soluções. Revista de Direito Sanitário. São Paulo, v. 5, n. 3, nov. p. 99-113, 2004.

MEIRELLES, Helly Lopes. Direito administrativo brasileiro. 18. ed. São Paulo: Malheiros Ed., 1993.

MOREIRA NETO, Diogo Figueiredo. Legitimidade e discricionariedade novas reflexões sobre os limites e controle da discricionariedade. 4. ed. Rio de Janeiro: Forense, 2002. 103 p.

RIO DE JANEIRO, 1986 (Municipio) Secretaria Municipal de Saúde, Decreto n. 6.235 , de 30 de outubro de 1986. Aprova o Regulamento da Defesa e proteção da Saúde no Tocante a Alimentos e à Higiene Habitacional e Ambiental. Diário Oficial do Municipio do Rio de Janeiro, 3 de novembro de 1986.

RIO DE JANEIRO, (Município) Secretaria Municipal de Saúde, Resolução n. 492, de 19 de outubro de 1994. Aprova e adota o Termo de Visita Sanitária. Diário Oficial do Município do Rio de Janeiro, 21 de outubro de 1994. 